\title{
BONE STRENGTH ESTIMATES RELATIVE TO VERTICAL GROUND REACTION FORCE DISCRIMINATES WOMEN RUNNERS WITH STRESS FRACTURE HISTORY
}

Kristin L. Popp ${ }^{1}$, William McDermott ${ }^{2}$, Julie M. Hughes ${ }^{3}$, Stephanie A. Baxter ${ }^{2}$, Steven D.

$$
\text { Stovitz }{ }^{4} \text {, Moira A. Petit }{ }^{1}
$$

${ }^{1}$ School of Kinesiology, Laboratory of Musculoskeletal Health, University of Minnesota, 1900 University Ave SE, Minneapolis, MN, USA 55455

${ }^{2}$ The Orthopedic Specialty Hospital, 5848 S Fashion Blvd, Murray, UT, USA 84107

${ }^{3}$ United States Army Research Institute of Environmental Medicine, 10 General Greene Ave, Natick, MA, USA 01760

${ }^{4}$ Department of Family Medicine and Community Health, University of Minnesota, 420 Delaware St. SE. MMC381, Minneapolis, MN, USA 55455

\section{Corresponding Author (present address)}

\section{Kristin Popp}

Endocrine Unit

50 Blossom Street

THR-1051

Boston, MA 02114

p. $612-432-8575$

f. 617-724-3299

kpopp@mgh.harvard.edu 


\section{Abstract}

Purpose: To determine differences in bone geometry, estimates of bone strength, muscle size and bone strength relative to load, in women runners with and without a history of stress fracture.

Methods: We recruited 32 competitive distance runners aged 18-35, with (SFX, $\mathrm{n}=16)$ or without (NSFX, $\mathrm{n}=16$ ) a history of stress fracture for this case-control study. Peripheral quantitative computed tomography (pQCT) was used to assess volumetric bone mineral density (vBMD, $\left.\mathrm{mg} / \mathrm{mm}^{3}\right)$, total (ToA) and cortical $(\mathrm{CtA})$ bone areas $\left(\mathrm{mm}^{2}\right)$, and estimated compressive bone strength (bone strength index; BSI, $\mathrm{mg} / \mathrm{mm}^{4}$ ) at the distal tibia. ToA, CtA, cortical vBMD, and estimated strength (section modulus; Zp, $\mathrm{mm}^{3}$ and strength strain index; SSIp, $\mathrm{mm}^{3}$ ) were measured at six cortical sites along the tibia. Mean active peak vertical (pkZ) ground reaction forces (GRFs), assessed from a fatigue run on an instrumented treadmill, were used in conjunction with pQCT measurements to estimate bone strength relative to load $\left(\mathrm{mm}^{2} / \mathrm{N}^{*} \mathrm{~kg}^{-1}\right)$ at all cortical sites. Results: SSIp and Zp were 9-11\% lower in the SFX group at mid-shaft of the tibia, while ToA and vBMD did not differ between groups at any measurement site. The SFX group had 11-17\% lower bone strength relative to mean pkZ GRFs $(\mathrm{p}<0.05)$. Conclusion: These findings indicate that estimated bone strength at the mid-tibia and mean pkZ GRFs are lower in runners with a history of stress fracture. Bone strength relative to load is also lower in this same region suggesting that strength deficits in the middle $1 / 3$ of the tibia and altered gait biomechanics may predispose an individual to stress fracture.

Key words: Peripheral Quantitative Computed Tomography (pQCT), volumetric bone mineral density (vBMD), cortical area, female, running mechanics. 


\section{1}

\section{Introduction}

Stress fracture is an overuse injury to bone tissue that occurs with repetitive loading and is thought to result from an imbalance between microdamage-driven bone remodeling and bone repair (16). Because stress fracture healing typically takes 6-12 weeks or longer, depending on the fracture grade and site (31), this injury is a concern among athletes (27), particularly runners $(25,37)$. The highest incidence of stress fracture is reported in members of track and field teams with rates from $10-31 \%$ per year $(11,23)$. Some research suggests that the incidence in women runners is twice that in their male counterparts (3).

Due to the risk of stress fractures among highly active populations, as well as the costly nature of the injury in terms of recovery time, it is important to understand the factors that cause an individual to be at greater susceptibility $(25,37)$. These factors generally fall into two categories: factors that affect bone strength (bone mineral density, bone geometry, age, genetics, nutrition, endocrine and hormonal status, exercise or loading history, and bone disease), and factors that influence the mechanical load on bone (gait biomechanics, changes in loading intensity and frequency, training surface, footwear, and body size and composition) $(5,22,41)$.

\footnotetext{
${ }^{11}$ Abbreviations: Stress fracture history (SFX), no history of stress fracture (NSFX), bone mineral density (BMD), areal bone mineral density (aBMD), volumetric bone mineral density (vBMD), total bone area (ToA), cortical bone area (CtA), bone strength index (BSI), section modulus (Zp), strength strain index (SSIp), ground reaction force (GRF), active peak vertical ground reaction force (pkZ), The Orthopedic Specialty Hospital (TOSH), muscle cross sectional area (MCSA)
} 
Numerous studies addressing stress fractures have focused on examining surrogates of bone strength - particularly bone mineral density (BMD) - to better understand stress fracture risk. The most widely utilized method of measuring BMD is through dual x-ray absorptiometry (DXA), which provides a two-dimensional or areal BMD (aBMD). Findings from cross sectional studies have yielded controversial results with some showing lower aBMD and some showing no difference or even higher aBMD in those with a history of stress fracture. $(4,8-10,13,14,19,30$, 39). There is evidence through both cross-sectional and prospective research suggesting that low aBMD, as a risk factor for stress fracture, may be more common in women than men $(8,10)$. In a prospective cohort study, female track and field athletes diagnosed with a stress fracture had lower aBMD of the lumbar spine compared to those who remained healthy (10). Importantly, although aBMD was lower in women who sustained a stress fracture, it was higher than or similar to bone density of less active women. This implies that women at risk of stress fracture in this cohort would not be identified as high risk based on normative DXA values.

Some findings suggest that geometric parameters (e.g. thinner cortices and narrow bones) may be more helpful for predicting stress fracture risk $(1,6-8,18,28,35,39)$. However, most of these studies have used bone geometry parameters also derived from DXA that fail to depict true bone tissue density and 3-dimensional geometry (17). Studies using computed tomography (CT) or low radiation measurement techniques such as peripheral quantitative computed tomography (pQCT), and high resolution peripheral quantitative computed tomography (HRpQCT), which are capable of assessing volumetric bone mineral density (vBMD) and 3-dimensional bone geometry, are lacking. 
pQCT and HRpQCT allow estimates of bone strength as well as muscle mass from crosssectional geometry. In a previous study conducted in our laboratory, we found significant deficits in $\mathrm{pQCT}$ derived estimated bone strength in women runners with a history of stress fracture (SFX) compared to those with no history of stress fracture (NSFX) (35). However, these differences disappeared after the estimated bone strength was adjusted for muscle size. Our findings suggested that bone strength was appropriately adapted to muscle size. Although there is a clear muscle-bone relationship, using muscle size alone as a measure of load imposed on bone eliminates factors of load that are affected by differences in gait mechanics between SFX and NSFX. Evaluating ground reaction forces (GRFs) during a run provides additional information with which to understand the biomechanical basis of stress fracture. If the bones adapt to loads imposed by habitual running (32), those runners who elicit higher vertical GRFs relative to body mass should theoretically have stronger bones. Vertical GRFs that occur during running are indicative of the load experienced by habitual runners (9). These GRFs can be used in combination with pQCT measurements to estimate bone strength relative to the loads imposed and should be considered when assessing stress fracture risk. We are unaware of any studies that have used pQCT derived strength values, at multiple sites of the tibia, relative to an individual's vertical GRFs during a continuous run.

Thus the purpose of our study was to: a) determine differences in vBMD and bone geometry, and b) use a force sensing treadmill in conjunction with bone measurements to assess differences in bone strength relative to load in competitive women distance runners with and without a history of stress fracture. We hypothesized that women distance runners with a history of stress fracture would have smaller cortical bone area (CtA), lower estimated bone strength, and lower estimated bone strength relative to load, than runners with no history of stress fracture. 


\section{2}

\section{Methods}

\subsection{1}

\section{Participants}

We recruited competitive women distance runners (ages 18-37) with $(n=16)$ and without $(n=16)$ a history of stress fracture from the Salt Lake City metropolitan area. "Competitive" was defined as having a competitive season(s) each year in which three or more races are completed. To be eligible for the study, athletes must run an average of 20 or more miles per week during their competitive season. Participants were recruited into a stress fracture group (SFX) and a non-stress fracture group (NSFX) depending on whether or not they had a medically diagnosed stress fracture by diagnostic imaging tests (bone scan, MRI or X-ray) in any bones of the lower limbs in five years prior to the study. In a screening questionnaire, potential participants were asked a series of questions related to basic health, stress fracture history, competition and training status. Participants were excluded if they had a stress fracture during the 12 months prior to the study (n $=2$ ), had a self-reported history of an eating disorder $(\mathrm{n}=1)$, medication use (other than oral contraceptives) known to influence bone metabolism, or were pregnant at the time of the study. A pregnancy test was administered to all participants prior to pQCT scans. This study was approved by the Internal Review Board (IRB) of the University of Minnesota, the University of Utah, and The Orthopedic Specialty Hopsital (TOSH) in Murray, UT. All participants signed an informed consent form in accordance with IRB guidelines prior to participation in the study.

Participants were required to visit the University of Utah Hospital for approximately one hour on one occasion. During this visit, following consent and anthropometry, bone health was assessed. 
Participants were required to make an additional visit to TOSH within one week of consent, for measurement of ground reaction forces during running.

\section{2 .2}

\section{Anthropometry}

We measured participant height to the nearest millimeter using a wall-mounted stadiometer (Health O Meter, Rye, NY) and mass to the nearest $0.1 \mathrm{~kg}$ on a calibrated electronic scale (Seca Model 840, Hanover, MD). We measured tibia length to the nearest millimeter using an anthropometric tape. All measurements were taken twice, and the mean of two measurements used.

\section{2 .3}

\section{Questionnaires}

We assessed training history, health history, sport-related injury, menstrual history and status, stress fracture history and past/current oral contraceptive use through questionnaires. The eating attitudes test (EAT-26) was used to screen for disordered eating and has been used in previous studies of runners $(2,21,34)$. These questionnaires were chosen to help assess whether there were group differences in factors known to influence stress fracture risk.

\subsection{4}

\section{Bone Measurements}

We used peripheral quantitative computed tomography (pQCT, XCT 2000, Stratec Medizintechnik GmbH, Pforzheim, Germany) to assess vBMD, geometry and estimated bone strength. Participants were required to sit with one leg extended for $\sim 30$ minutes for each limb. 
pQCT scans were taken at the distal region (4\% of the tibia length) and along the midshaft (15\%, $25 \%, 33 \%, 45 \%, 50 \%$, and $66 \%$ ) of each tibia. Each participant's leg was positioned using a customized leg holder (Bone Diagnostic Inc.). A Velcro strap was used to ensure each participant's leg remained stationary during scan acquisition. We determined the reference line by acquisition of a $30 \mathrm{~mm}$ planar scout view of the joint line. All pQCT analyses were based on a sampling resolution (voxel size) of $0.4 \mathrm{~mm}$ and a scan speed of $25 \mathrm{~mm} / \mathrm{sec}$, according to the manufacturer's recommendations. To analyze the $4 \%$ site we used contour mode $3\left(200 \mathrm{mg} / \mathrm{cm}^{3}\right)$, peel mode 5 (automatic) and cort mode $3\left(200 \mathrm{mg} / \mathrm{cm}^{3}\right)$. This highly trabecular site of the tibia was assessed for total bone cross-sectional area $\left(\mathrm{ToA}, \mathrm{mm}^{2}\right)$ and total vBMD $\left(\mathrm{mg} / \mathrm{mm}^{3}\right)$. Bone strength was estimated using the bone strength index $\left(\mathrm{BSI}, \mathrm{mg} / \mathrm{mm}^{4}\right)$ calculated as ToA*vBMD 2 /100,000. The cortical regions $(15 \%-66 \%)$ of the tibia were assessed using contour mode 1 (710 $\left.\mathrm{mg} / \mathrm{cm}^{3}\right)$, peel mode $2\left(540 \mathrm{mg} / \mathrm{cm}^{3}\right)$, and cort mode $1\left(710 \mathrm{mg} / \mathrm{cm}^{3}\right.$ and $480 \mathrm{mg} / \mathrm{cm}^{3}$ for polar strength strain index (SSip)). We calculated ToA, CtA $\left(\mathrm{mm}^{2}\right)$, and cortical vBMD $\left(\mathrm{mg} / \mathrm{cm}^{3}\right)$. The polar strength-strain index $\left(\mathrm{SSI}_{\mathrm{p}}, \mathrm{mm}^{3}\right)$ and section modulus $\left(\mathrm{Zp}, \mathrm{mm}^{3}\right)$ were used to estimate bone strength. Muscle cross sectional area (MCSA) was measured at the $66 \%$ site as this is typically the area associated with the largest calf muscle belly (36). Our assessment of MCSA included all lower limb muscles that are in the $66 \%$ cross-section of the tibia and was determined based on thresholds to define tissue borders of bone, skeletal muscle, and subcutaneous fat. We used contour mode $1\left(-100 \mathrm{mg} / \mathrm{cm}^{3}\right)$, peel mode $2\left(40 \mathrm{mg} / \mathrm{cm}^{3}\right)$ and cort mode $1\left(710 \mathrm{mg} / \mathrm{cm}^{3}\right)$. Total exposure to ionizing radiation for each participant was 1.8 millirem.

One trained operator (KP) performed all measurements as well as the scan analysis. Quality assurance was performed daily using the cone phantom provided by the manufacturer. Because there are currently no standardized analysis protocols for pQCT studies analyzing the present 
target population, the modes and thresholds used in this study are based on the manufacturer's recommendations.

\section{2 .5}

\section{Fatigue Run}

We used a high-speed force-sensing motorized treadmill (Treadmetrix, Park City, UT) to collect ground reaction forces during an exhaustive treadmill run. This custom designed, lightweight treadmill has 3D force transducers (MC3A AMTI, Watertown, MA) at each corner that interface with amplifiers (MSA6 AMTI, Watertown, MA) allowing continuous measurements of ground reaction forces during multiple footfalls.

The exhaustive run was performed at each individual's predicted $5 \mathrm{k}$ race pace, based on previous race performances. This is a pace that is assumed to be greater than anaerobic threshold pace and assumed to elicit fatigue $(12,15)$. Because experienced runners are accustomed to various types of warm-up runs and stretches, participants were allowed 15 minutes to complete a self-selected warm-up. Upon completion of the warm-up, the treadmill was set to each individual's predetermined pace. Participants were asked to run to volitional fatigue with a goal of reaching 910 on a Rate of Perceived Exertion scale (scaled from 1-10). To monitor fatigue, heart rate and Rate of Perceived Exertion were recorded once every minute for the duration of the run and blood lactate levels were collected immediately after the run. We used C-motion visual 3D motion analysis software (C-Motion, Inc., Germantown, MD) to manage and report outcomes. All GRFs were collected at $1000 \mathrm{~Hz}$ and lowpass filtered at $25 \mathrm{~Hz}$ using a $4^{\text {th }}$ order Butterworth filter. The main variable of interest was active peak vertical (pkZ) GRF. We chose the active peak because it has been associated with the largest compressive and sheer loading of the posterior tibia (38). 
pkZ GRFs were collected during the first 10 seconds ( 20-24 footfalls) of each minute and normalized for body mass $\left(\mathrm{N} * \mathrm{~kg}^{-1}\right)$. For each 10 second collection period, we calculated a mean pkZ GRF for both the left and the right leg ( 10-12 footfalls each). In order to make betweenparticipant comparisons throughout the duration of the run, we normalized collection points into a relative percent of the fatigue run $(0 \%, 10 \%, 20 \%, 30 \%, 40 \%, 50 \%, 60 \%, 70 \%, 80 \%, 90 \%$, and $100 \%$ ). To do this we used the mean pkZ GRF collected during the minute nearest to each $10 \%$ of the total run length (i.e. for a 17 minute run each $10 \%$ segment represents 1.7 minutes thus we used the mean pkZ GRF of minutes $0,2,3,5,7,9,10,12,14,15$, and 17 for analysis).

\subsection{6}

Bone Strength Relative to Load

In order to assess tibia strength in relation to mean pkZ GRFs during running, we adapted Selker et al.'s theory regarding the scaling of long bone fracture strength with body mass (40). Selker suggests, based on the beam theory, that in animals with different body sizes, the strength of a long bone generally scales as the section modulus over bone length. We adapted this equation and calculated the polar strength strain index (SSIp), which is a density-weighted section modulus. We divided this by a surrogate for lever arm (the product of total tibia length and percent length of the tibia at which SSIp was calculated.). This gives us a measure of bone strength. To express bone strength relative to load we divided bone strength by ground mean pkZ GRFs.

relative bone strength $=\frac{\left(S S I_{p\left(m m^{3}\right)} / \operatorname{Length}_{T i b i a(m m)} x\right)}{\text { mean } p k Z G R F_{\left(N k_{k}{ }^{1)}\right.}}$ $x=$ percent tibia length 


\subsection{7}

\section{Statistical Analyses}

Data were summarized by means (95\% Confidence Interval) unless specified otherwise. Participant characteristics were compared using unpaired t-tests. Between-group differences in contraceptive use and menstrual cycles per year were compared using the Fisher's exact test. While SFX and NSFX groups reported similar miles run per week and years of training, they differed by age, body mass, and height. To control for these factors, bone outcomes were adjusted for age, body mass and tibia length. Differences in baseline bone parameters, regardless of left or right limb, were compared using a random-effects general linear model treating left and right measures as a pair of repeated measures and to adjust for age, body mass, and tibia length, wherein the individual participant specific intercepts were allowed to vary at random. Analysis of covariance (ANCOVA) was applied to compare differences in left limb and right limb baseline bone parameters and bone strength relative to load. In an additional statistical model, we added MCSA as a covariate to determine if differences in bone geometry and strength remained after MCSA was controlled for. Finally, to compare differences in left and right mean pkZ GRFs between SFX and NSFX groups throughout the duration of the fatigue run, we compared the means over time using random intercept longitudinal general linear model with variance component error structure. A two-sided $\mathrm{p}<0.05$ was considered statistically significant. 


\section{3}

\section{Results}

\subsection{1}

Demographics and Training History

Values for descriptive variables for the women in both the SFX and NSFX groups are displayed in Table 1. Two participants (one from each group) were unable to complete the fatigue run. One became injured after completing pQCT measurements, the other overestimated her current fitness and only completed 3 minutes of the run. They were excluded from the analysis leaving us with 15 runners in each group. Participants ranged in age from 18-39 years, weighed 47.4-72.8 kg and had normal body mass index $\left(17-24 \mathrm{~kg} / \mathrm{m}^{2}\right)$. Participants had been running for 4-31 years and ran between $6.5-10 \mathrm{mph}$ during the fatigue run. Mean values were similar between groups for most variables although the SFX group was slightly younger (4 years, $\mathrm{p}<0.05)$, shorter $(5 \mathrm{~cm}, \mathrm{p}<0.05)$, and lighter $(5.5 \mathrm{~kg}, \mathrm{p}<0.01)$ than the NSFX group. There was no significant differences in Eat-26 scores between groups and no scores were indicative of eating disorders. Contraceptive use, age of menarche and menstrual status were similar between groups. Women in the SFX group selfreported stress fractures in the femur $(n=5)$, tibia or fibula $(n=25)$ and bones in the foot $(n=8)$. Nine women had a history of 2 or more stress fractures and eight had experienced a stress fracture on both their right and left limbs. 
Table 1. Demographic characteristics of female runners with (SFX) and without (NSFX) a history of stress fracture. Values are Mean (95\% Confidence Interval)

\begin{tabular}{|c|c|c|c|}
\hline & $\begin{array}{c}\text { SFX } \\
n=15\end{array}$ & $\begin{array}{l}\text { NSFX } \\
\mathrm{N}=15\end{array}$ & $\begin{array}{c}\text { p- } \\
\text { value }\end{array}$ \\
\hline Age (yrs) & $27.0(24.3,29.7)$ & $30.9(28.2,33.5)$ & $0.05^{*}$ \\
\hline Height $(\mathrm{cm})$ & $164.8(162.1,161.7)$ & $169.8(167.1,172.5)$ & $0.04 *$ \\
\hline Body Mass (kg) & $54.8(52.1,57.4)$ & $60.3(57.6,62.9)$ & $0.004 *$ \\
\hline BMI $\left(\mathrm{kg} / \mathrm{m}^{2}\right)$ & $20.2(19.3,21.1)$ & $20.9(20.0,21.8)$ & 0.30 \\
\hline Tibia Length (mm) & $367.9(356.8,379.1)$ & $375.9(364.8,387.1)$ & 0.31 \\
\hline Average Miles Run Per Week & $25.6(18.3,32.9)$ & $28.1(20.8,35.4)$ & 0.63 \\
\hline Plyometric Training (hrs/wk) & $0.4(0.1,0.8)$ & $0.4(0.1,0.8)$ & 1.00 \\
\hline Weight Training (hrs/wk) & $1.9(0.8,3.1)$ & $1.8(0.7 .2 .9)$ & 0.87 \\
\hline Years of Training & $14.7(11.4,18.0)$ & $14.9(11.6,18.2)$ & 0.89 \\
\hline Fatigue Run Speed (mph) & $8.1(7.5-8.6)$ & $7.7(7.1-8.3)$ & 0.39 \\
\hline Time to Fatigue (min) & $18.7(15.8-21.5)$ & $16.0(13.8-18.2)$ & 0.12 \\
\hline Eat 26 & $4.3(2.2,6.4)$ & $6.2(4.1,8.3)$ & 0.21 \\
\hline Age of Menarche & $13.5(12.6,14.5)$ & $13.5(12.5,14.4)$ & 1.00 \\
\hline Contraceptives (yes/no) & $12 / 3$ & $12 / 3$ & 1.00 \\
\hline Cycles/year & & & 0.53 \\
\hline$<4$ & 1 & 2 & \\
\hline $4-10$ & 2 & 4 & \\
\hline$\geq 10$ & 12 & 9 & \\
\hline
\end{tabular}

*significantly different from stress fracture group $(\mathrm{p}<0.05)$

\subsubsection{Bone}

Bone strength indices in both the left and the right tibia were similar to findings of the combined left and right limb analysis. In the general linear model combined analysis the SFX group had significantly lower Zp at the $45 \%$ and $50 \%$ sites, SSIp at the $50 \%$ site, CtA at the $15 \%$ and $45 \%$ sites and MSCA (Table 2) compared to the NSFX group. In the separate right and left leg analysis (ANCOVA) bone strength was also significantly lower in the SFX group within the middle third of the tibia (45-50\% sites) for Zp (-9 to $-12 \%)$ and (50\% site) SSIp (-10 to -11\%). We detected significantly smaller CtA at the $15 \%$ site in both left and right tibia (-7\%) and at the $45 \%$ site $(-7 \%)$ in the left tibia. Total bone area and vBMD did not differ or approach statistically significant differences between groups at any site. Muscle cross-sectional area (MCSA) of the right leg was $8 \%$ lower $(\mathrm{p}=0.03$ ) in the SFX group than the NSFX group but we saw no significant difference in MCSA in the left leg $(\mathrm{p}=0.06)$. Because of differences found in both the 
combined and separate limb analyses, we added MCSA as a covariate to the models. After

adjusting for MCSA, there were no longer significant differences between groups at any

measured site in either analysis.

Table 2. Tibia bone volumetric density, geometry and estimated strength in female runners with (SFX) and without (NSFX) a history of stress fracture. Values are adjusted for age, mass, and tibia length and presented as mean and mean (95\% confidence interval).

\section{Group}

\begin{tabular}{|c|c|c|c|c|c|c|c|c|c|}
\hline & \multirow[t]{2}{*}{ Parameter } & \multirow[t]{2}{*}{$\begin{array}{c}\text { Delta } \\
* *\end{array}$} & \multirow{2}{*}{$\underset{* *}{\mathbf{p}-}$} & \multicolumn{2}{|c|}{$\begin{array}{l}\text { SFX } \mathbf{n}=\mathbf{1 5} \\
\text { mean*(CI) }\end{array}$} & \multicolumn{2}{|c|}{$\begin{array}{c}\mathbf{N S F X} \mathbf{n}=\mathbf{1 5} \\
\text { mean } *(\mathrm{CI})\end{array}$} & \multicolumn{2}{|c|}{ p-value } \\
\hline & & & & Left & Right & Left & Right & Left & Right \\
\hline \multirow{3}{*}{$4 \%$} & Total Area $\left(\mathrm{mm}^{2}\right)$ & 52.0 & 0.18 & $931.2(870.0,992.4)$ & $926.7(868.0,985.5)$ & $988.9(927.7,1050)$ & $969(910.8,1028.3)$ & 0.19 & 0.31 \\
\hline & $\mathrm{BMD}\left(\mathrm{mg} / \mathrm{mm}^{3}\right)$ & 4.7 & 0.70 & $321.2(303.9,338.5)$ & $325.9(306.4,345.5)$ & $319.8(302.5,337.1)$ & $322.1(302.5,341.6)$ & 0.91 & 0.78 \\
\hline & BSI $\left(\left(\mathrm{mg} / \mathrm{mm}^{4}\right) / 1,000,000\right)$ & 2.5 & 0.72 & $96.2(86.2,106.1)$ & $98.7(87.9,109.0)$ & $101.3(91.4,111.2)$ & $101.1(89.8,111.1)$ & 0.47 & 0.80 \\
\hline \multirow[t]{5}{*}{$15 \%$} & Total Area $\left(\mathrm{mm}^{2}\right)$ & 15.9 & 0.41 & $391.8(362.9,420.7)$ & $393.3(363.4,423.3)$ & $405.9(377.0,434.8)$ & $409.9(379.5,439.4)$ & 0.48 & 0.45 \\
\hline & Cortical Area $\left(\mathrm{mm}^{2}\right)$ & 14.04 & $0.01 *$ & $173.9(165.1,182.8)$ & $174.5(165.8,183.3)$ & $187.8(179.0,196.7)$ & $188.6(179.9,197.3)$ & $0.03 *$ & $0.03 *$ \\
\hline & Cortical Density $\left(\mathrm{mg} / \mathrm{mm}^{3}\right)$ & 8.1 & 0.13 & $1162(1153,1171)$ & $1159(1151,1167)$ & $1169(1161,1178)$ & $1168.2(1160,1177)$ & 0.26 & 0.12 \\
\hline & $\operatorname{SSIp}\left(\mathrm{mm}^{3}\right)$ & 119.6 & 0.13 & $1369(1249,1489)$ & $13589(1239,1478)$ & $1485(1365,1604)$ & $1476(1357,1596)$ & 0.17 & 0.17 \\
\hline & Section Modulus $\left(\mathrm{mm}^{3}\right)$ & 117.3 & 0.13 & $1320(1203,1437)$ & $1317(1198,1437)$ & $1439(1322,1556)$ & $1431(1312,1551)$ & 0.16 & 0.18 \\
\hline \multirow[t]{5}{*}{$25 \%$} & Total Area $\left(\mathrm{mm}^{2}\right)$ & 12.1 & 0.34 & $335.8(316.6,355.1)$ & $337.5(316.8,358.1)$ & $345.1(325.9,364.3)$ & $352.8(332.2,373.4)$ & 0.50 & 0.30 \\
\hline & Cortical Area $\left(\mathrm{mm}^{2}\right)$ & 13.2 & 0.09 & $229.1(217.9,240.3)$ & $230.7(218.2,243.1)$ & $240.0(228.8,251.2)$ & $245.8(233.3,258.2)$ & 0.17 & 0.09 \\
\hline & Cortical Density $\left(\mathrm{mg} / \mathrm{mm}^{3}\right)$ & 1.0 & 0.91 & $1202(1192,1211)$ & $1199(1189,1211)$ & $1203(1194,1213)$ & $1200(1189,1211)$ & 0.80 & 1.00 \\
\hline & $\operatorname{SSIp}\left(\mathrm{mm}^{3}\right)$ & 76.1 & 0.29 & $1380(1273,1488)$ & $1408(1293,1522)$ & $1440(1333,1547)$ & $1500(1385,1614)$ & 0.43 & 0.26 \\
\hline & Section Modulus $\left(\mathrm{mm}^{3}\right)$ & 89.0 & 0.22 & $1325(1221,1430)$ & $1357(1241,1473)$ & $1392(1288,1496)$ & $1469(1353,1585)$ & 0.37 & 0.18 \\
\hline \multirow[t]{5}{*}{$33 \%$} & Total Area $\left(\mathrm{mm}^{2}\right)$ & 13.9 & 0.24 & $348.4(331.4,365.3)$ & $355.4(336.1,374.8)$ & $363.3(346.3,380.3)$ & $369.2(349.9,388.6)$ & 0.22 & 0.31 \\
\hline & Cortical Area $\left(\mathrm{mm}^{2}\right)$ & 13.0 & 0.14 & $268.8(256$ & $273.7(2$ & $2,294.7)$ & $286.9(2$ & 0.15 & 0.21 \\
\hline & Cortical Density $\left(\mathrm{mg} / \mathrm{mm}^{3}\right)$ & 0.8 & 0.91 & $1203(1194,1212)$ & $1198(1186.6,1210.3)$ & $1203(1194,1212)$ & $1196.9(1185,1209)$ & 1.00 & 0.85 \\
\hline & $\operatorname{SSIp}\left(\mathrm{mm}^{3}\right)$ & 84.6 & 0.20 & $1493(1399,1588)$ & $1519(1408,1629)$ & $1583(1488,1678)$ & $1602(1492,1713)$ & 0.19 & 0.29 \\
\hline & Section Modulus $\left(\mathrm{mm}^{3}\right)$ & 99.5 & 0.16 & $1452(1353,1552)$ & $1495(1378,1612)$ & $1560(1460,1660)$ & $1590(1473,1708)$ & 0.13 & 0.26 \\
\hline \multirow[t]{5}{*}{$45 \%$} & Total Area $\left(\mathrm{mm}^{2}\right)$ & 24.0 & 0.07 & $395.4(376.3,414.6)$ & $398.0(367.6,419.4)$ & $417.5(398.4,436.7)$ & $423.2(401.7,444.6)$ & 0.11 & 0.10 \\
\hline & Cortical Area $\left(\mathrm{mm}^{2}\right)$ & 22.8 & $0.05^{*}$ & $302.1(285.1,319.2)$ & $304.1(285.2,322.9)$ & $322.6(305.6,339.7)$ & $328.9(310.0,247.7)$ & $0.01 *$ & 0.06 \\
\hline & Cortical Density $\left(\mathrm{mg} / \mathrm{mm}^{3}\right)$ & 0.7 & 0.93 & $1189(1178,1200)$ & $1189(1176,1201)$ & $1190(1179,1202)$ & $1186(1173,1199)$ & 0.86 & 0.71 \\
\hline & $\operatorname{SSIp}\left(\mathrm{mm}^{3}\right)$ & 163.8 & 0.06 & $1714(1592,1836)$ & $1722(1580,1864)$ & $1868(1746,1990)$ & $1886(1744,2028)$ & 0.08 & 0.12 \\
\hline & Section Modulus $\left(\mathrm{mm}^{3}\right)$ & 191.0 & $0.03^{*}$ & $1692(1571,1811)$ & $1681(1534,1829)$ & $1860(1740,1980)$ & $1891(1743,2038)$ & $0.05^{*}$ & $0.05^{*}$ \\
\hline \multirow[t]{5}{*}{$50 \%$} & Total Area $\left(\mathrm{mm}^{2}\right)$ & 22.6 & 0.13 & $412.7(390.2,435.1)$ & $420.8(397.4,444.2)$ & $438.1(415.7,460.5)$ & $441.1(417.7,464.5)$ & 0.12 & 0.22 \\
\hline & Cortical Area $\left(\mathrm{mm}^{2}\right)$ & 22.8 & 0.07 & $306.8(288.1,325.5)$ & $312.5(292.5,332.5)$ & $329.9(311.2,348.6)$ & $334.2(314.2,354.1)$ & 0.09 & 0.13 \\
\hline & Cortical Density $\left(\mathrm{mg} / \mathrm{mm}^{3}\right)$ & 2.0 & 0.78 & $1183(1172,1194)$ & $1176(1163,1188)$ & $1186(1175,1196)$ & $1177(1164,1190)$ & 0.75 & 0.90 \\
\hline & $\operatorname{SSIp}\left(\mathrm{mm}^{3}\right)$ & 240.7 & $0.03 *$ & $1753(1571,1935)$ & $1810(1645,1976)$ & $2038(1856,2220)$ & $2023(1837,2169)$ & $0.03 *$ & $0.04 *$ \\
\hline & Section Modulus $\left(\mathrm{mm}^{3}\right)$ & 203.3 & $0.04 *$ & $1790(1645,1934)$ & $1820(1666,1975)$ & $2011(1866,2156)$ & $2006(1852,2161)$ & $0.04 *$ & $0.05 *$ \\
\hline \multirow[t]{6}{*}{$66 \%$} & Total Area $\left(\mathrm{mm}^{2}\right)$ & 23.4 & 0.25 & $518.0(486.9,549.0)$ & $519.9(488.1,551.8)$ & $545.4(514.4,576.4)$ & $537.0(505.2,568.8)$ & 0.22 & 0.45 \\
\hline & Cortical Area $\left(\mathrm{mm}^{2}\right)$ & 18.1 & 0.12 & $302.7(284.6,320.8)$ & $307.2(289.2,325.1)$ & $319.3(301.3,337.4)$ & $325.8(307.9,343.7)$ & 0.20 & 0.15 \\
\hline & Cortical Density $\left(\mathrm{mg} / \mathrm{mm}^{3}\right)$ & 8.3 & 0.22 & $1158(1147,1169)$ & $1154(1143,1164)$ & $1163(1152,1174)$ & $1165(1154,1175)$ & 0.48 & 0.14 \\
\hline & $\operatorname{SSIp}\left(\mathrm{mm}^{3}\right)$ & 231.3 & 0.07 & $2257(2069,2446)$ & $2254(2054,2454)$ & $2493(2304,2681)$ & $2445(2245,2645)$ & 0.08 & 0.18 \\
\hline & Section Modulus $\left(\mathrm{mm}^{3}\right)$ & 197.4 & 0.16 & $2302(2091,2512)$ & $2320(2104,2536)$ & $2511(2300,2722)$ & $2476(2260,2692)$ & 0.17 & 0.31 \\
\hline & Muscle CSA $\left(\mathrm{mm}^{2}\right)$ & 396.4 & $0.03^{*}$ & $4852(4582,5121)$ & $4884(4608,5160)$ & $5215(4945,5484)$ & $5327(5051,5603)$ & 0.06 & $0.03 *$ \\
\hline
\end{tabular}

*Significantly higher than the SFX group $(\mathrm{p}<0.05)$

** Difference in the combined left and right limb means between the SFX group and NSFX

group after adjusting for age, mass, and tibia length 


\subsection{3}

\section{Ground Reaction Forces}

Throughout the fatigue run, there were no significant within group differences in mean pkZ GRFs when comparing the beginning of the run to the end (Figure 1). Each participant reached a blood lactate level of $>4$ mmol. l $^{-1}$, suggesting fatigue was achieved (33). Differences in, mean pkZ GRFs in the SFX group were approximately $3 \%$ higher $(\mathrm{p}=0.006)$ on the left leg (Figure 1$)$ and $4 \%$ higher $(\mathrm{p}=0.001)$ on the right leg (data not shown) throughout the entire run compared to the NSFX group.

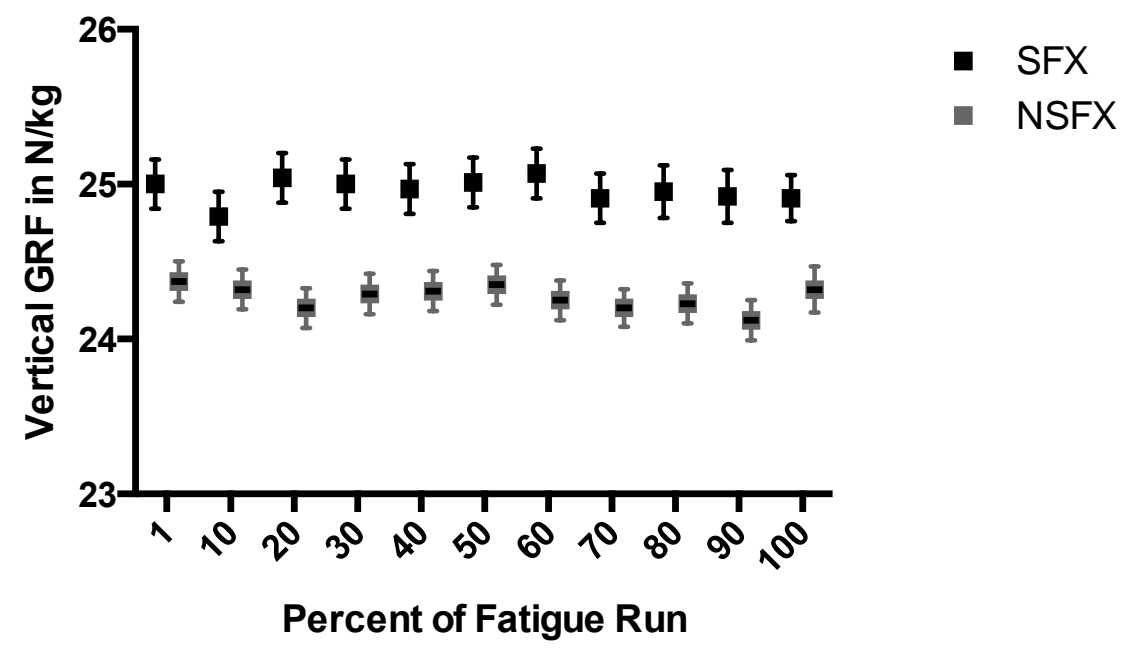

Fig. 1. Mean active peak vertical (pkZ) ground reaction forces (GRFs) between groups: Mean (SEM) pkZ GRFs $(\mathrm{N})$ for the left limb, normalized by body mass $(\mathrm{kg})$ measured at the beginning $(0 \%)$ and at each $10 \%$ of a fatiguing run in women runners with (SFX) and without (NSFX) a history of stress fracture.

\subsection{4}

\section{Relative Bone Strength}

Because mean PkZ GRFs did not change in either leg or in either group throughout the duration of the run we chose to use the values collected at the $50 \%$ time point in the fatigue run. Using the mean pkZ GRF at $50 \%$ of the run and SSIp at each cortical tibia site to calculate relative bone 
strength, there were no significant differences between SFX and NSFX groups at the three most distal tibial sites $(15 \%, 25 \%, 33 \%)$. In contrast, the SFX group had lower bone strength relative to mean pkZ GRFs in both the left and right tibias at the $45 \%$ (-11\%,to -13\%), 50\% (-16\%) and $66 \%$ $(-10 \%$,to $-12 \%)$ sites (Table 3, Fig 2). These between group differences were similar using the mean pkZ GRF at $0 \%$ and $100 \%$ of the run (data not shown).

Table 3. - Relative bone strength $\left(\mathrm{mm}^{2} / \mathrm{N}^{*} \mathrm{~kg}^{-1}\right)$ in female runners with (SFX) and without (NSFX) a history of stress fracture, at six measurement sites (15\%-66\%) of the tibia. Values are Mean (95\% Confidence Interval).

Group

\begin{tabular}{cccccccc}
\hline \multirow{2}{*}{ Site } & \multicolumn{2}{c}{$\begin{array}{c}\text { SFX n=15 } \\
\text { mean*(CI) }\end{array}$} & \multicolumn{2}{c}{$\begin{array}{c}\text { NSFX N=15 } \\
\text { mean*(CI) }\end{array}$} & \multicolumn{2}{c}{$\begin{array}{c}\text { p-value } \\
\text { Left }\end{array}$} & Right \\
\hline $15 \%$ & $0.99(0.89-1.09)$ & $0.98(0.88-1.07)$ & $1.08(1.00-1.16)$ & $1.03(0.98-1.17)$ & 0.16 & 0.12 \\
$25 \%$ & $0.60(0.54-0.65)$ & $0.60(0.56-0.65)$ & $0.63(0.59-0.67)$ & $0.66(0.60-0.71)$ & 0.37 & 0.11 \\
$33 \%$ & $0.49(0.45-0.52)$ & $0.49(0.46-0.52)$ & $0.53(0.50-0.55)$ & $0.53(0.50-0.57)$ & 0.06 & 0.07 \\
$45 \%$ & $0.41(0.38-0.43)$ & $0.40(0.38-0.43)$ & $0.46(0.43-0.48)$ & $0.46(0.42-0.50)$ & $0.006 *$ & $0.007 *$ \\
$50 \%$ & $0.38(0.34-0.41)$ & $0.38(0.36-0.41)$ & $0.45(0.41-0.49)$ & $0.44(0.40-0.48)$ & $0.007 *$ & $0.02 *$ \\
$66 \%$ & $0.37(0.34-0.04)$ & $0.37(0.34-0.40)$ & $0.41(0.39-0.44)$ & $0.42(0.39-0.44)$ & $0.03 *$ & $0.02 *$ \\
\hline
\end{tabular}

* Significantly higher than the SFX group $(\mathrm{p}<0.5)$

\section{4}

\section{Discussion}

We assessed tibial vBMD, bone geometry (total and cortical bone area) and estimates of bone strength by pQCT in women distance runners with and without a history of stress fracture. We also measured mean pkZ GRFs during a fatiguing run using a 3-dimensional force-sensing treadmill. Our analysis found that women runners with a history of stress fracture had significantly lower measures of tibial bone strength at the $45 \%$ and $50 \%$ sites of the tibia. Consistent with our previous study on a separate group of runners (35), when adjusting for muscle size, bone strength was no longer significantly different between the groups with and 
without a history of stress fracture. However, bone strength relative to the mean pkZ GRF during running was substantially lower in the stress fracture group at the mid-shaft of the tibia.

\subsection{1}

\section{Bone strength differences}

A major finding of this study is that pQCT estimates of bone strength in the tibia tend to be lower in runners with a history of lower limb stress fractures compared to runners without a history of stress fracture. We used section modulus (Zp) and the polar strength strain index (SSIp) as indices of bone strength for this study. Those measures are highly correlated with 3-point bending strength in laboratory models (26). Both measures of bone strength outcomes were lower in the stress fracture group at one or more mid-shaft tibia sites. There were no differences in vBMD or total bone area at any measure site. However, there was a significant difference in CtA at the $15 \%$ and $45 \%$ sites. Our results are similar to findings of our previous research in which we found significantly higher $\mathrm{CtA}$ at the $45 \%, 50 \%$ and $66 \%$ sites, and SSIp at the 50\% and $66 \%$ sites in the NSFX group (35). While we were adequately powered to detect differences between groups in our primary research question, bone strength relative to load, we estimate we would have needed 29 runners in each group to detect a statistical difference in $\mathrm{CtA}$ at the $50 \%$ and $66 \%$ sites. Our findings are also consistent with studies from other laboratories that used 2-dimensional technology such as radiographs and DXA to estimate bone geometry by deriving cortical dimensions to estimate area moments of inertia (28). In two separate studies, Beck et al. $(7,8)$ found smaller cross sectional moments of inertia and section moduli at the femoral neck and tibia among male and women military recruits who experienced a stress fracture as well as thinner cortices in women fracture cases. In contrast, Bennell et al. (9) used computerized tomography (CT) to estimate bone strength differences in female running athletes with and without a stress 
fracture and found no significant differences in any bone strength or geometric outcome between groups. In that study, CT measurements were taken only at the $33 \%$ site of the tibia. By assessing multiple sites along the length of the tibia, our data show that differences in bone strength are smaller at the more distal sites of the tibia (below $45 \%$ site), which may explain the lack of difference in the paper by Bennell et al.(9).

\subsection{2}

\section{Bone strength relative to load}

While bone strength, structure and muscle size can be important in predicting stress fracture risk (8), perhaps even more important is the determination of bone strength relative to the external loads imposed. It is possible that individuals at risk for stress fracture have bone strength values that are similar to those who are not at risk. However, if bone is not adequately robust for the specific loads that are placed on it, strength may not be as important as strength relative to the applied load. Adjusting bone measurements statistically, based on muscle measurements is one method of estimating the strength relative to load relationship. After adjustment for muscle size, significant differences in bone strength were no longer apparent. This suggests that the strength and structure of bones of both groups are well adapted to muscle size. However, gait involves biomechanical measures such as joint moments, impact forces, GRFs and changes in GRFs due to muscular fatigue that are unaccounted for by static bone and muscle geometric measurements.

We chose to measure mean pkZ GRFs and changes in mean pkZ GRFs with fatigue as primary factors that are not accounted for from static measurements. pkZ GRFs are not a direct measure of the strain on bone, however they provide an approximation of the load acting on the tibia during gait $(9,14,19,20)$ and are a more direct assessment of bone strain than muscle size alone. While 
we did not see a difference with fatigue, our data indicate that mean pkZ GRFs were significantly higher (3-4\%) in the SFX group than the NSFX group throughout the fatigue run. Similarly, bone strength relative to mean pkZ GRFs was significantly lower (-10 to -16\%) in the SFX group than the NSFX at the mid-tibia sites (45-66\%). This suggests that runners with a history of stress fracture at any lower limb site, experience greater loads at the tibia during running, and may help explain their predisposition to stress fracture. Importantly, these relationships are missed when static measurements alone are studied. Future studies regarding stress fracture risk should investigate additional dynamic gait indices in relation to bone strength. Several biomechanical factors have been associated with increased stress fracture risk in female runners. Recent evidence suggests higher rates of loading during early stance and higher free moments (a measure of torsion between the foot and the ground) are associated with stress fracture risk. Peak rearfoot eversion and peak hip adduction have also been shown to increase stress fracture risk. These high rates of loading, larger degrees of movement, and greater measures of free moment may result in increased load experienced by the tibia during running.

\subsection{3}

\section{Site Specific Differences}

Congruent with our previous study (35), we found site-specific differences in tibial bone strength, showing lower strength in the SFX group compared to the NSFX group at $45 \%$ and $50 \%$ sites. In both studies, bone strength was related to MCSA. Given this consistency between two separate cohorts of runners, we speculate that muscle size and strength are important factors in the development of stress fractures. Our current study extends those findings by showing that tibial bone strength is actually low in SFX relative to mean pkZ GRFs. Interestingly, we found no significant between-group differences at distal sites $(15 \%, 25 \%$, and $33 \%)$ in either study. The 
strength deficits in the SFX group at the mid-shaft correspond with the region of the tibia that is associated with the highest prevalence of stress fractures (29). This pattern may point to an important region in the tibia to help identify individuals at high risk for tibial stress fractures and highlight the importance of assessing bone structure and strength relative to the loads placed on them when investigating skeletal pathologies.

\subsection{4}

\section{Limitations and Strengths}

The cross-sectional, case-control design of this study is a limitation as data points were measured at only one point in time, and thus we are not able to examine causal relationships. The cases and controls were all very active in the running community and were recruited from the same geographic location. We did not control for nutrition, sleep, or training factors, other than weekly mileage, that may affect stress fracture risk. All but one participant was Caucasian, limiting the generalizability of our results to other races. Although age was slightly different between the groups, both groups had been training for a similar number of years, and achieved menarche ten or more years prior, and the number of cycles per year were similarly distributed between groups. We did not measure menstrual cycle or ovulatory status - both known to impact bone quality(24).

\section{5}

\section{Conclusion}

In conclusion, our data reveal that women runners with a history of stress fracture have lower bone strength in the middle third of the tibia and smaller muscle cross-sectional area. The difference in bone strength is not significant after adjusting for muscle size, suggesting a welladapted muscle-bone relationship in both groups. However, women runners with a history of 
stress fracture have significantly lower bone strength relative to the loads they encounter during running, suggesting that suboptimal bone geometry and lower bone strength relative to load during running may predispose an individual to stress fracture. Further research is needed to determine whether altering biomechanics to decrease pkZ GRFs is a viable solution to reduce injury risk in women with a history of stress fracture.

\section{Acknowledgments}

The authors would like to acknowledge the National Athletic Trainers Association (NATA) for funding this study. This work was also supported by an appointment to the Postgraduate Research Participation Program at the U.S. Army Research Institute of Environmental Medicine administered by the Oak Ridge Institute for Science and Education through interagency agreement between the U.S. Department of Energy and U.S. Army Medical Research and Material Command (J.M.H.) We would like to thank the staff at The Orthopedic Specialty Hospital (TOSH) in Murry, UT for the use of their equipment, and contributions that allowed successful completion of the study. Thank you to Dr. Laurie Moyer-Mileur at the University of Utah, for the use of her pQCT machine. Thank you to Dr. Mary Bouxsein at Beth Israel Deaconess Medical Center for editorial and statistical guidance. Finally, we would like to thank the runners who participated in this study.

Funding: This work is supported by the National Athletic Trainers Association [grant number CON000000012723] 


\section{Disclaimer}

The views, opinions, and/or findings in this report are those of the authors, and should not be construed as an official Department of the Army position, policy, or decision, unless so designated by other official documentation.

\section{References}

1. Ackerman KE, Cano Sokoloff N, G DENM, Clarke HM, Lee H, Misra M. Fractures in Relation to Menstrual Status and Bone Parameters in Young Athletes. Med Sci Sports Exerc. 2015;47(8):1577-86.

2. Araujo MP, Oliveira E, Zucchi EV, Trevisani VF, Girao MJ, Sartori MG. [The relationship between urinary incontinence and eating disorders in female long-distance runners]. Rev Assoc Med Bras. 2008;54(2):146-9.

3. Arendt EA, Agel J, Heikes C, Griffiths H. Stress injuries to bone in college athletes; a retrospective review of experience at a single institution. Am J Sports Med. 2003;31:35968.

4. Armstrong DW, 3rd, Rue JP, Wilckens JH, Frassica FJ. Stress fracture injury in young military men and women. Bone. 2004;35(3):806-16.

5. Beck BR. Tibial stress injuries. An etiological review for the purposes of guiding management. Sports Med. 1998;26:265-79.

6. Beck BR, Rudolph K, Matheson GO, Bergman AG, Norling TL. Risk factors for tibial stress injuries: a case-control study. Clin J Sport Med. 2015;25(3):230-6.

7. Beck TJ, Ruff CB, Mourtada FA et al. Dual-energy X-ray absorptiometry derived structural geometry for stress fracture prediction in male U.S. Marine Corps recruits. $J$ Bone Miner Res. 1996;11(5):645-53.

8. Beck TJ, Ruff CB, Shaffer RA, Betsinger K, Trone DW, Brodine SK. Stress fracture in military recruits: gender differences in muscle and bone susceptibility factors. Bone. 2000;27(3):437-44.

9. Bennell K, Crossley K, Jayarajan J et al. Ground reaction forces and bone parameters in females with tibial stress fracture. Med Sci Sports Exerc. 2004;36(3):397-404.

10. Bennell KL, Malcolm SA, Thomas SA et al. Risk factors for stress fractures in track and field athletes. A twelve-month prospective study. Am J Sports Med. 1996;24(6):810-8.

11. Bennell KL, Malcolm SA, Thomas SA, Wark JD, Brukner PD. The incidence and distribution of stress fractures in competitive track and field athletes. A twelve-month prospective study. Am J Sports Med. 1996;24(2):211-7.

12. Borrani F, Candau R, Perrey S, Millet GY, Millet GP, Rouillon JD. Does the mechanical work in running change during the VO2 slow component? Med Sci Sports Exerc. 2003;35(1):50-7.

13. Carbon R, Sambrook PN, Deakin V et al. Bone density of elite female athletes with stress fractures. Med J Aust. 1990;153(7):373-6. 
14. Crossley K, Bennell KL, Wrigley T, Oakes BW. Ground reaction forces, bone characteristics, and tibial stress fracture in male runners. Med Sci Sports Exerc. 1999;31(8):1088-93.

15. Derrick TR, Dereu D, McLean SP. Impacts and kinematic adjustments during an exhaustive run. Med Sci Sports Exerc. 2002;34(6):998-1002.

16. Evans RK, Antczak AJ, Lester M, Yanovich R, Israeli E, Moran DS. Effects of a 4-month recruit training program on markers of bone metabolism. Med Sci Sports Exerc. 2008;40(11 Suppl):S660-70.

17. Evans RK, Negus C, Antczak AJ, Yanovich R, Israeli E, Moran DS. Sex differences in parameters of bone strength in new recruits: beyond bone density. Med Sci Sports Exerc. 2008;40(11 Suppl):S645-53.

18. Giladi M, Milgrom C, Simkin A et al. Stress fractures and tibial bone width. A risk factor. J Bone Joint Surg Br. 1987;69(2):326-9.

19. Grimston SK, Engsberg JR, Kloiber R, Hanley DA. Bone mass, external loads and stress fractures in female runners. International Journal or Sport Biomechanics. 1991;7:292302.

20. Grimston SK, Nigg BM, Fisher V, Agemian SV. External loads throughout a 45 minute run in stress fracture and non-stress fracture runners. Journal of Biomechanics. 1994:668.

21. Hopkinson RA, Lock J. Athletics, perfectionism, and disordered eating. Eat Weight Disord. 2004;9(2):99-106.

22. Hughes J, Popp K, Yanovich R, Bouxsein M, Matheny Jr R. The role of adaptive bone formation in the etiology of stress fracture. Experimental Biology and Medicine. 2016.

23. Johnson AW, Weiss CB, Jr., Wheeler DL. Stress fractures of the femoral shaft in athletes-more common than expected. A new clinical test. Am J Sports Med. 1994;22(2):248-56.

24. Kalyan S, Prior JC. Bone changes and fracture related to menstrual cycles and ovulation. Crit Rev Eukaryot Gene Expr. 2010;20(3):213-33.

25. Li GP, Zhang SD, Chen G, Chen H, Wang AM. Radiographic and histologic analyses of stress fracture in rabbit tibias. Am J Sports Med. 1985;13(5):285-94.

26. Liu D, Manske SL, Kontulainen SA et al. Tibial geometry is associated with failure load ex vivo: a MRI, pQCT and DXA study. Osteoporos Int. 2007;18(7):991-7.

27. Matheson G, Clement D, McKenzie D, Taunton J, Lloyd-Smith D, Macintyre J. Sress fractures in athletes; a study of 320 cases. Am J Sports Med. 1987;15:46-58.

28. Milgrom C, Giladi M, Simkin A et al. The area moment of inertia of the tibia: A risk factor for stress fractures. In: Proceedings of the J. Biomechanics 1989. p. 1243-8.

29. Monteleone GP, Jr. Stress fractures in the athlete. Orthop Clin North Am. 1995;26(3):42332.

30. Myburgh KH, Hutchins J, Fataar AB, Hough SF, Noakes TD. Low bone density is an etiologic factor for stress fractures in athletes. Ann Intern Med. 1990;113(10):754-9.

31. Nattiv A, Kennedy G, Barrack MT et al. Correlation of MRI grading of bone stress injuries with clinical risk factors and return to play: a 5-year prospective study in collegiate track and field athletes. Am J Sports Med. 2013;41(8):1930-41.

32. Nikander R, Kannus P, Rantalainen T, Uusi-Rasi K, Heinonen A, Sievanen H. Crosssectional geometry of weight-bearing tibia in female athletes subjected to different exercise loadings. Osteoporos Int. 2010;21(10):1687-94.

33. Nikooie R. Determination of anaerobic threshold by monitoring the $\mathrm{O} 2$ pulse changes in endurance cyclists. J Strength Cond Res. 2015. 
34. Okano G, Holmes RA, Mu Z, Yang P, Lin Z, Nakai Y. Disordered eating in Japanese and Chinese female runners, rhythmic gymnasts and gymnasts. Int J Sports Med. 2005;26(6):486-91.

35. Popp KL, Hughes JM, Smock AJ et al. Bone geometry, strength, and muscle size in runners with a history of stress fracture. Medicine and Science in Sports and Exercise. 2009;41(12):2145-50.

36. Rittweger J, Beller G, Ehrig J et al. Bone-muscle strength indices for the human lower leg. Bone. 2000;27(2):319-26.

37. Roub LW, Gumerman LW, Hanley EN, Jr., Clark MW, Goodman M, Herbert DL. Bone stress: a radionuclide imaging perspective. Radiology. 1979;132(2):431-8.

38. Sasimontonkul S, Bay, B., Pavol, M. . Bone contact forces on the distal tibia during the stance phase of running. Journal of Biomechanics. 2007.

39. Schnackenburg KE, Macdonald HM, Ferber R, Wiley PJ, Boyd SK. Bone quality and muscle strength in female athletes with lower limb streses fractures. Med Sci Sports Exerc. 2011;43(11):2110-9.

40. Selker F, Carter DR. Scaling of long bone fracture strength with animal mass. J Biomech. 1989;22(11-12):1175-83.

41. Warden SJ, Davis IS, Fredericson M. Management and prevention of bone stress injuries in long-distance runners. J Orthop Sports Phys Ther. 2014;44(10):749-65. 